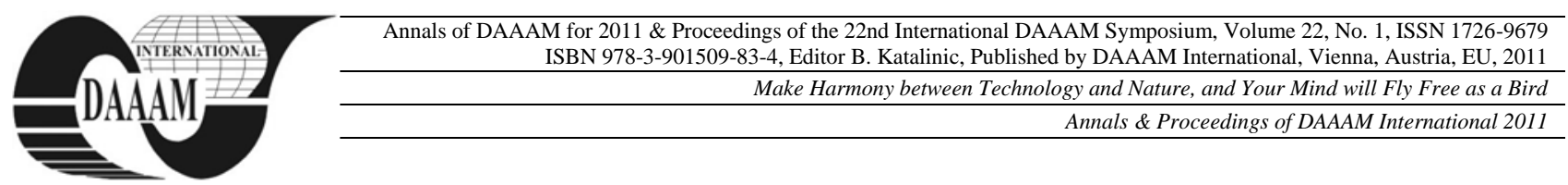

\title{
AUTONOMOUS POSITIONING BASED ON MACHINE VISION
}

\author{
FERIANCIK, M[iloslav] \& LISKA, O[ndrej]
}

\begin{abstract}
Paper deals with the control of the autonomous movement of positioning device (robot) with using the machine vision. It focuses on creating control software for autonomous movements i.e. transfer and execution of the operation according to the algorithm trajectory. Using the account information on the identification and location of the object positioning obtained using machine vision techniques.
\end{abstract}

Key word: control, autonomy, software, machine vision, robot

\section{INTRODUCTION}

Positioning and manipulation with objects belong to the basic tasks in production and non- production automatization.New opportunities for control and feedback movement of pointing device are created by adding a visual system to the pointing device (industrial robot, manipulator).The combination of vision systems and robotics has the potential for increase the effectiveness of automated manufacturing processes and for use of robotic systems in areas previously not considered as automated.

\section{AN AUTONOMOUS POSITIONING SYSTEM BASED ON MACHINE VISION}

The systems using processing of image are used in various production and non-production processes. The term machine vision is nowadays used for the process of computer vision in industrial automation.

The basic structure of such a system is formed by a pointing device (eg an industrial robot or manipulator), which is supposed to move subjects from one (starting) position to the second (final) position, and camera system. The camera system consists of a web camera and identifying application. The role of the identifying application is to detect the searched object and to determine its coordinates. Grasping objects with the manipulator is guided by the camera.

The proposed system for autonomous positioning with using of machine vision lies in the fact that the whole system is controlled by one control application. It will consist of two basic parts:

- of processes of image processing such as recognition, detection of object and the following processes associated with, - the processes connected with the control of pointing device and his movement.

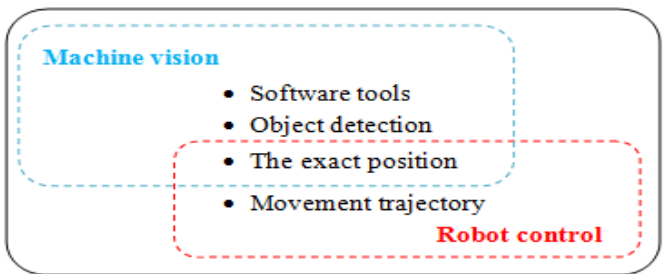

Fig. 1. Diagram of the layout of sub-tasks to create complex application for robot control using machine vision
In the proposed solution it will be not necessary to deal with configuration between separate applications, which will perform only a partial operations of the whole process. Control application communicate directly with the robot control system,and thereby it is avoiding the programming language, so it becomes usable for many types of robots -it is universal. The program for movement of the robot will be predefined, for his introduction to a particular operation will be necessary to change only a few reference positions. Installation and configuration of such a system for autonomous positioning do not require highly skilled personnel. An important requirement is that the system should be capable of rapid introduction into service.

\section{ROBOT CONTROL SOFTWARE WITH USING MACHINE VISION}

When solving autonomous positioning with using machine vision, several problems raise. One of the most common problems are high demands on computing hardware and software. In standard applications, as a mean of recording commercial cameras with sensitive optics for detailed imaging of objects are used.Their price is much higher compared with the proposed concept solution using a webcam. For the simple task of recognizing and determining the position it can meet their functional parameters. Another advantage is that it has a USB (Universal Serial Bus) interface, which is readily available and installation is simple.

In machine vision applications, problems arise in the selection of tools for image processing. Each application can be interpreted as a combination of successive elementary tasks. These elementary tasks can be solved by tools that include graphic libraries. The advantage of graphic libraries, unlike graphic programs is the ability to create own application. They contain many features and a wide range of tools for image interpretation.

The control system is a software application on the PC, which is guaranteed to meet the requirements on computing hardware and create sufficient backups for the increasing performance of tasks. The big advantage is the complexity of the management software, which covers several areas for the solution of the whole task. Processes related to image processing and evaluation, and management of industrial manipulator, therefore its movement are basic processes. Between the separate programs from which the system is composed, it is necessary to solve their compatibility. By complexity of the management software we can avoid issues with compatibility in various subprograms.

Another problem which needs to be solved in such a role is the calibration of the camera coordinate system with robot coordinate system. Information about the exact position or distance of the object detected by image processing requires a coordinate system in which the data were obtained to be identical with the coordinate system used by the robot. Practically it is never possible to orientate the camera so that it 
coordinates to be identically with the coordinates of the robot. The image can be rotated, skewed perspective or affected by other disturbances. Transformation of coordinates of camera view to the coordinates of the robot is a solution for unification of coordinate system. And therefore it is necessary to propose an algorithm to determine the proper transformation coefficients. They may apply only to defined camera position and scene. For each camera moving to a new position it is necessary to change the transformation coefficients.

There are several ways and methods of motion control of robots and manipulators. Information about the coordinates of the captured object is obtained by processing the scanned image. This position represents the final position of the effector. By using methods of motion control it is necessary to propose an algorithm for autonomous generation of effector trajectory.

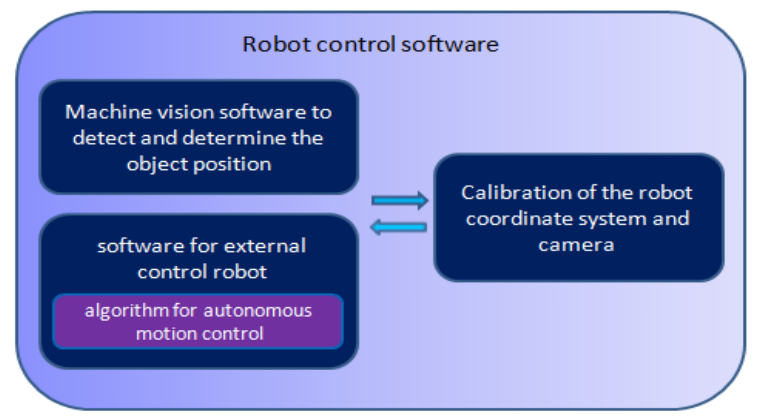

Fig. 2. Synthesis of the programs into a single control application

\section{SOFTWARE TO CONTROL THE ROBOT}

In the development environment Microsoft Visual Studio 2008 in programming language $\mathrm{C} \#$ to develop program in training center, which will run all the processes necessary to ensure the autonomous positioning based on machine vision.

To communicate with the PC controller of Mitsubishi robot $\mathrm{RV}-2 \mathrm{AJ}$ can be used standard interface RS-232C or Ethernet network interface (TCP/ IP), of which the advantage is connection to the control unit via the Internet and transfer of arrangements and long-distance service. In the first phase of development of applications a serial interface RS-232C was used For Compatibility of control unit with PC it was necessary to adjust individual values for baud rate, setting the bits, parity check to check accuracy of data and stop bits to end the communication. An important step for managing the robot is necessarilly a proper control of internal commands for managing and checking the control unit of robot and commands for the robot programming language. The movement of the robot is provided by sending individual commands.

In the next stage of the program will be a solution of other operations as a continuous movement through a few points, for its security we need to gather information of the current state of the robot. It must be sent by request in a repeated interval. The solution of next stage is closely related with integration of computer vision tasks. On the picture 19 there is an example of application on external robot control tested by device Mitsubishi RV-2AJ. In the control window are shown functions setting values for the serial connection, boxes for entering values of coordinates, keys with the pre-defined commands to activate the robot control unit, servoturn, move the robot to the position specified by coordinates and button for opening and closing effector.

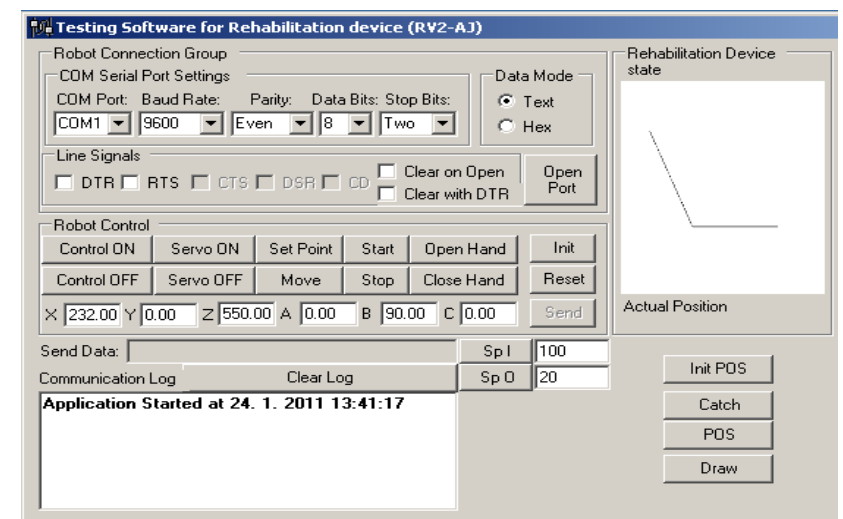

Fig. 3. Software to control the robot

\section{CONCLUSION}

The article deals with the design and implementation of comprehensive control software for managing industrial robot (positioning system) using machine vision. The structure of the system is described and it consists of the processes of image processing and management of positioning device.

Many unpredictable situations may occur in the application of the autonomous positioning based on machine vision. For example, change of the scene illumination, an obstacle in the robot workspace, bad designed algorithm etc. For optimal results all of these problems and errors need to be solved.

\section{ACKNOWLEDGEMENTS}

The research work is supported by the Project of the Structural Funds of the EU, Operational Program Research and Development, Measure 2.2 Transfer of knowledge and technology from research and development into practice: Title of the project: Research and development of the intelligent nonconventional actuators based on artificial muscles ITMS code: 26220220103.

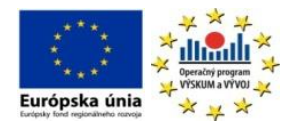

We are support research activities in Slovakia / Project is cofounded from sources of ES.

\section{REFERENCES}

Kragic, D. - Christensen, H. I.: Survey on Visual Servoing for Manipulation. Centre for Autonomous Systems, Numerical Analysis and Computer Science, Sweden

Havle, O. - Strojové vidění I: Principy a charakteristiky, Machine vision I: Principles and characteristics, AUTOMA $1 / 2008$

Havle, O. - Strojové vidění II: Úlohy, nástroje a algoritmy, Machine Vision II: Tasks, tools and algorithms, AUTOMA $2 / 200$

Juršica, L., Hubinský, P., Kardoš, J.: Robotika, Robotics, Slovenská technická univerzita v Bratislave, Fakulta elektrotechniky a informatiky, 2005

Mitsubishi Industial Robot, RV-1A/2AJ Series, Robot Arm Setup \& Maintenance, 2007, Tokyo, Japan, p462. Mitsubishi Industial Robot, CR1/CR2/CR3/CR4/CR7/CR8/CR9 Controller, Detailed explanations of functions and operations, 2007, Tokyo, Japan, p72.

Virius M.:C\# - Hotové řesení, C\# - Ready-made solutions, Brno, Computer Press, 2006, ISBN: 80-251-1084-2 